\title{
Dermatitis de contacto por Paederus en un niño de 12 años
} Contact Paederus Dermatitis in a 12 years old boy

\author{
Dra. Betina Pagotto ${ }^{a}$ Dra. Romina Plafnik ${ }^{a}$, Dra. Andrea Castillo ${ }^{a}$, Dra. Jimena Cionci ${ }^{a}$, \\ Dra. María Eugenia Abad ${ }^{b}$ Dra. María Silvina Cabanillas ${ }^{a}$ y Prof. Dra. Margarita Larralde
}

\section{RESUMEN}

La dermatitis por Paederus es un tipo particular de dermatitis de contacto causada por la pederina contenida en la hemolinfa de un pequeño insecto del género Paederus. Se caracteriza por una erupción vesicopustulosa sobre una base eritematosa de rápida aparición, en zonas descubiertas, con el antecedente de exposición al aire libre. El diagnóstico se realiza por las manifestaciones clínicas típicas y el contexto epidemiológico. El objetivo de esta publicación es presentar un caso clínico, y evaluar la epidemiologia y las manifestaciones clínicas de la dermatitis de contacto por Paederus.

Palabras clave: Paederus, pederina, dermatitis de contacto, insectos.

\section{SUMMARY}

Paederus dermatitis is a peculiar contact dermatitis caused by pederine contained in the hemolimph of a small insect of the genus Paederus. It is characterized by vesico-pustulous eruption arising over an erythematous background, of sudden onset, over exposed areas of the body, and the history of outdoor activities. Diagnosis is based on the typical clinical features and the epidemiological context.

The aim of this publication is to report a case and evaluate theepidemiological and clinical characteristics of Paederus dermatitis. Key words: Paederus, pederine, contact dermatitis, insects.

http:/ /dx.doi.org/10.5546/aap.2013.e66

\section{INTRODUCCIÓN}

La dermatitis por Paederus es una forma particular de dermatitis de contacto, caracterizada por lesiones eritematovesiculosas de inicio súbito, localizadas en zonas expuestas del cuerpo. ${ }^{1}$ Es causada por una sustancia llamada pederina, contenida en la hemolinfa de un pequeño insecto del género Paederus. ${ }^{1,2}$

La disposición característica de las lesiones y el contexto epidemiológico contribuyen al diagnóstico.

a. Sección Dermatología Pediátrica, Hospital Ramos Mejía.

b. Servicio de Dermatología, Hospital Alemán.

c. Sección Dermatología Pediátrica, Hospital Ramos Mejía y Servicio de Dermatología, Hospital Alemán.

Correspondencia:

Dra. Betina Pagotto: betina.pagotto@gmail.com

Conflicto de intereses: Ninguno que declarar.

Recibido: 29-10-2012

Aceptado: 8-3-2013

\section{CASO CLÍNICO}

Un niño de 12 años, en buen estado general y afebril, consultó a la Sección de Dermatología Pediátrica del Hospital Ramos Mejía, por presentar una placa eritematosa única, amplia, de bordes definidos, sobre la que asentaban pequeñas pápulas y pústulas, no fluctuante, localizada en la región lateral derecha del cuello, de 3 días de evolución; se acompañaba de leve prurito, pero era indolora. No presentaba adenopatías regionales (Figura 1). Había acudido a una guardia, donde se le indicó cefalexina en dosis de $100 \mathrm{mg}$ / $\mathrm{kg} /$ día; en el momento de la consulta cursaba el primer día de tratamiento. En el interrogatorio se destacaba que, 48 horas antes a la aparición de las lesiones, el niño había participado en actividades recreativas al aire libre en la colonia de verano del club, en la zona de Caseros, en el Gran Buenos Aires, y no se había aplicado repelente. Con las manifestaciones clínicas y la epidemiología se arribó al diagnóstico de dermatitis de contacto por Paederus, se indicó tratamiento con corticosteroides tópicos de mediana potencia en una aplicación diaria, cetirizina una vez por día como antihistamínico y se suspendió la cefalexina. Las lesiones mejoraron a las 72 horas.

Figura 1. Placa eritematosa, con pequeñas pústulas y fina descamación localizada en la región laterocervical

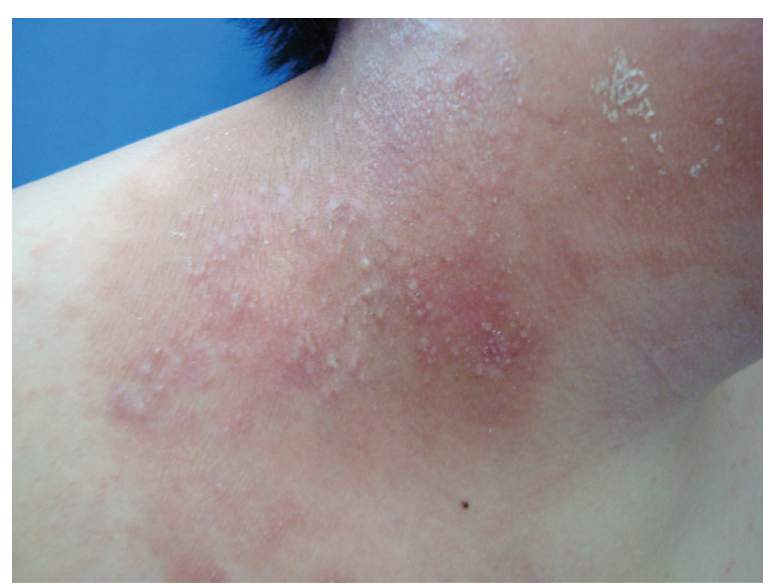




\section{DISCUSIÓN}

El insecto causante de esta dermatitis es muy pequeño y pertenece al género Paederus, familia Staphylinidae, orden Coleoptera. Existen más de 622 especies distribuidas mundialmente, aunque predomina en áreas tropicales y subtropicales. ${ }^{1,2}$ Se han detectado brotes de dermatitis por Paederus en Australia, Malasia, Sri Lanka, Nigeria, Kenia, Irán, África Central, Uganda, Okinawa, Sierra Leona, Argentina, Brasil, Perú, Venezuela, Ecuador e India. ${ }^{3,4}$ En América Latina se la conoce como "latigazo", por su semejanza con la lesión lineal que produce el látigo en la piel. ${ }^{4}$

En la Argentina, se lo incluyó en el Programa Nacional de Riesgos Químicos del Departamento de Salud Ambiental en 2006, ${ }^{5}$ a pesar de lo cual no hay casos informados de dermatitis por Paederus en el país desde 1960. En 1915, Baliña describió por primera vez la lesión producida por Paederus sin conocer en ese momento su agente etiológico, que fue reconocido en 1936. En el verano 19581959 se registraron más de 100 casos de dermatitis por Paederus. ${ }^{6,7}$ La última serie de casos comunicados en Latinoamérica datan de 1999; se trata de 1451 casos notificados en el departamento de Piura, Perú, relacionados con el fenómeno climático de El Niño, que provocó un aumento de precipitaciones en la región. ${ }^{4}$

Paederus tiene hábitos nocturnos y es atraído por fuentes de luz artificial, como las luces fluorescentes, se activa durante la noche y a temperaturas mayores de $20^{\circ} \mathrm{C}$. La lesión fue conocida como "dermatitis de los vigilantes", ya que era común observarla en vigilantes nocturnos que trabajaban debajo de las fuentes de luz. ${ }^{8}$ Su número aumenta después de las lluvias, al elevarse la humedad, por lo que es más frecuente en el verano. ${ }^{9}$

Los adultos miden 7 a $10 \mathrm{~mm}$ de largo, son alargados, tienen una cabeza con dos antenas y un abdomen inferior, ambos de color negro, y un tórax colorado. Tienen alas y pueden volar, pero prefieren correr y son muy ágiles. Tienen el hábito característico de arquear hacia arriba el abdomen cuando corren o son molestados, un dato de utilidad para su identificación ${ }^{3,10}$ (Figura 2).

Paederus no muerde, no pica ni produce lesiones sólo por caminar sobre la piel. Sin embargo, al ser aplastado en forma accidental sobre la piel, se produce la liberación de hemolinfa que contiene pederina, un fuerte irritante capaz de causar una dermatosis vesicular inflamatoria. ${ }^{3,9}$ La sustancia química pederina fue aislada por primera vez por Pavan y Bo, en $1952 .^{2}$
En la dermatitis de contacto por Paederus se reconocen cuatro etapas:

- Inicio: en las primeras 24 a 48 horas se presenta edema, eritema y, a veces, pápulas y prurito.

- Evolución: a partir de las 48 horas continúa con eritema, se forman vesículas o ampollas que pueden tornarse purulentas. Entre el quinto y el octavo día, la toxina se difunde y da lugar a lesiones secundarias alrededor de la lesión primaria, que pueden confundirse con contaminación bacteriana. En esta etapa puede haber dolor, fiebre y malestar general.

- Regresión: a partir de los 8 días disminuye el eritema, se forman costras y luego caen.

- Regeneración total: desaparece el eritema, se reduce el tamaño de la costra, que finalmente cae entre los 20 y los 35 días. No deja cicatriz, sólo una hiperpigmentación residual que desaparece después de 5 días más. ${ }^{3,8,11}$

Las lesiones en ocasiones adquieren una disposición lineal, lo cual constituye una clave para el diagnóstico y se conoce como signo del "latiga$\mathrm{zo}^{\prime \prime}{ }^{4}$ Puede acompañarse de sensación de prurito, ardor o quemazón. ${ }^{11}$ Es frecuente que haya más de una lesión. 2,3,12 Una forma de presentación característica son las lesiones "en beso", que ocurren por la aposición de la zona afectada con piel intacta, como puede observarse en las flexuras o en la cara interna de los muslos. ${ }^{3,12}$

Las lesiones se localizan con mayor frecuencia en la mitad superior del cuerpo, principalmente la cara y el cuello. Cuando compromete la región periocular, la transferencia del irritante desde las lesiones cutáneas puede ocasionar compromiso ocular en forma de queratoconjuntivitis, llamado "ojo de Nairobi". ${ }^{13}$ También se han observado casos de queratoconjuntivitis sin compromiso cutáneo. ${ }^{13}$ No es infrecuente la afectación de la región genital por la transferencia de la pederina a través de las manos. ${ }^{4,10,12}$ La complicación más observada es la hiperpigmentación residual; la sobreinfección bacteriana y la ulceración son infrecuentes. ${ }^{3}$

Figura 2. Paederus (Gentileza Dr. Castillo) 
La dermatitis por Paederus suele confundirse con herpes simple y herpes zóster, de los que se diferencia por la presencia de vesículas con disposición en ramilletes aislados o metaméricos. El impétigo ampollar se distingue por tener ampollas flácidas que se destechan fácilmente y parecen una quemadura de cigarrillo. Las fitofotodermatosis presentan lesiones lineales en los miembros, eccematosas, producidas por el contacto de una sustancia irritante procedente de una planta y la exposición lumínica. El prurigo agudo por picaduras se manifiesta con seropápulas pruriginosas, en zonas expuestas, principalmente en los meses de verano. La dermatitis por contacto alérgica, la dermatitis artefacta y las quemaduras por líquidos son otros de los diagnósticos diferenciales para considerar. ${ }^{1,2,9}$

El diagnóstico se basa en la presencia de las manifestaciones clínicas típicas, con disposición lineal o en espejo, de inicio súbito, con sensación de quemazón o ardor, localizadas en zonas expuestas del cuerpo, asociadas al contexto epidemiológico. ${ }^{1,9}$

Aunque el diagnóstico es fundamentalmente clínico, en los casos dudosos se puede realizar el estudio anatomopatológico para confirmarlo. En la histopatología se puede observar espongiosis y exocitosis de neutrófilos, vesículas intraepidérmicas y necrosis epidérmica, con edema dérmico $\mathrm{y}$ un infiltrado inflamatorio intersticial y perivascular. $^{11}$

\section{TRATAMIENTO}

El manejo es el recomendado para una dermatitis de contacto: eliminar el agente irritante, lavar con agua y jabón, y aplicar compresas húmedas. Los antibióticos sólo se utilizan si hay una infección secundaria. Los antihistamínicos orales y los corticosteroides tópicos son útiles para aliviar los síntomas. ${ }^{1,9}$

El mejor método para prevenir las lesiones es evitar el contacto con Paederus. Es necesario aprender a reconocerlo y evitar aplastarlo sobre la piel. Las medidas ambientales incluyen la colocación de mallas en las puertas y ventanas para prevenir la entrada del insecto, dormir bajo un mosquitero tratado con permetrina y colocar mallas alrededor de las fuentes de luz para prevenir la caída de los insectos. Luego de utilizar un insecticida es necesario eliminar las carcasas mediante el barrido. Se debe recomendar a los pacientes no aplastar el insecto sobre la piel, sino sacarlo suavemente con un papel., ${ }^{2,9}$

\section{CONCLUSIONES}

La dermatitis de contacto por Paederus es una entidad que debe ser considerada frente a lesiones de inicio súbito, pruriginosas, en zonas expuestas del cuerpo, compuestas por vesículas o pustulosas, con disposición lineal o en espejo en los sitios de pliegues. Contribuyen en forma importante al diagnóstico el antecedente de estadía en lugares con densa vegetación y clima húmedo, o la cercanía a fuentes de luz artificial, así como la aparición de casos semejantes en la misma zona.

El conocimiento de esta dermatosis es importante tanto para el médico como para el paciente a fin de evitar diagnósticos erróneos y tratamientos innecesarios. La educación de la comunidad contribuye a la disminución de su incidencia y a su prevención con la simple aplicación de medidas tendientes a evitar el contacto con el insecto.

\section{BIBLIOGRAFÍA}

1. Vanhecke C, Malvy D, Guevart E, Lalogue V, Ezzedine K. Dermatite à Paederus: étude rétrospective de 74 cas survenus en 2008 à Conakry, Guinée. Ann Dermatol Vénéréol 2010;137(3):189-93.

2. Gnanaraj P, Venugopal V, Kuzhal Mozhi M, Pandurangan N. An outbreak of Paederus dermatitis in a suburban hospital in South India: a report of 123 cases and review of literature. J Am Acad Dermatol 2007;57(2):297-300.

3. Singh G, Yousurf Ali S. Paederus Dermatitis. Indian J Dermatol Venereol Leprol 2007;73(1):13-5.

4. Alva-Dávalos V, Laguna-Torres VA, Huamán A, Olivos R, et al. Dermatite epidêmica por Paederus irritans em Piura, Perú, 1999, relacionada ao fenómeno El Niño. Rev Soc Bras Med Trop 2002;35(1):23-8.

5. Argentina. Ministerio de Salud de la Nación. Nociones básicas sobre animales venenosos de la Republica Argentina: elementos para su reconocimiento y medidas de primeros auxilios en caso de accidente. Programa Nacional de Riesgos Químicos. Departamento de Salud Ambiental. Dirección de Promoción y Protección de la Salud Buenos Aires, 2006. Disponible en http://www.sertox.com.ar/ img/guia_animales_venenosos.pdf.

6. Kaminsky A, Kaplan H, Axenfeld J. Dermatitis por Paederus. Rev Asoc Med Argent 1960;74:195-6.

7. Cordero AA, Vivot NA, Molina EB. Dermatitis vesicofluctenular por Paederus. Una epidemia durante el verano 1958-1959. Prensa Med Argent 1958;45:3944-7.

8. Guillén Z, Solano L, Pareja E. Los insectos Paederus (Coleóptera-Staphylinidae) causantes de dermatitis de contacto en el Perú. Rev Peru Med Trop 2004;9:27-31.

9. Huang C, Liu Y, Yang J, Tian J, et al. An outbreak of 268 cases of Paederus dermatitis in a toy-building factory in central China. Int J Dermatol 2009;48(2):128-31.

10. García Rivas L, Parra JJ, Reyes Flores O. Dermatitis por Paederus en el Estado Cojedes, Venezuela. Derm Venez 2001;39(4);93-8.

11. Assaf M, Nofal E, Nofal A, Assar O, Azmy A. Paederus dermatitis in Egypt: a clinicopathological and ultrastructural study. J Eur Acad Dermatol Venereol 2010;24(10):1197-201.

12. Zargari O, Kimayi-Asadi A, Fathalikhani F, Panahi M. Paederus dermatitis in northern Iran: a report of 156 cases. Int J Dermatol 2003;42(8):608-12.

13. Huang F, Chen W, Shih M. Paederus-Induced Keratitis. Cornea 2010;29(8):941-3. 